\title{
Third structure determination by powder diffractometry round robin (SDPDRR-3)
}

A. Le Bail ${ }^{\text {a) }}$

Laboratoire des Oxydes et Fluorures, Université du Maine, CNRS UMR 6010, Av. O. Messiaen, 72085 Le Mans, France

L. M. D. Cranswick

Chalk River Laboratories, Canadian Neutron Beam Centre, National Research Council Canada, Building 459, Chalk River, Ontario KOJ 1J0, Canada

K. Adil

Laboratoire des Oxydes et Fluorures, Université du Maine, CNRS UMR 6010, Av. O. Messiaen, 72085 Le Mans, France

\author{
A. Altomare \\ Istituto di Cristallografia, CNR, Via G. Amendola, 122/o, 70126 Bari, Italy
}

M. Avdeev

Bragg Institute, Australian Nuclear Science and Technology Organisation, Building 87, PMB 1, Menai, New South Wales 2234, Australia

R. Cerny

Laboratoire de Cristallographie, 24, quai Ernest-Ansermet, CH-1211 Geneva 4, Switzerland

C. Cuocci and C. Giacovazzo

Istituto di Cristallografia, CNR, Via G. Amendola, 122/o, 70126 Bari, Italy

I. Halasz

Department of Chemistry, Faculty of Science, University of Zagreb, Horvatovac 102a, 10000 Zagreb, Croatia

S. H. Lapidus

Department of Physics and Astronomy, Stony Brook University, Stony Brook, New York 11794-3800, USA

J. N. Louwen

Research Center Catalysts, Albemarle Corporation, P.O. Box 37650, 1030 BE Amsterdam, The Netherlands

A. Moliterni

Istituto di Cristallografia, CNR, Via G. Amendola, 122/o, 70126 Bari, Italy

L. Palatinus

Laboratoire de Cristallographie, Le Cubotron, Ecole Polytechnique Fédérale de Lausanne, 1015 Lausanne, Switzerland

R. Rizzi

Istituto di Cristallografia, CNR, Via G. Amendola, 122/o, 70126 Bari, Italy

E. C. Schilder

Research Center Catalysts, Albemarle Corporation, P.O. Box 37650, 1030 BE Amsterdam, The Netherlands

P. W. Stephens and K. H. Stone

Department of Physics and Astronomy, Stony Brook University, Stony Brook, New York 11794-3800, USA

J. van Mechelen

Laboratory of Crystallography, University of Amsterdam, Valckenierstraat 65, 1018XE Amsterdam,

The Netherlands

(Received 15 April 2009; accepted 28 May 2009)

The results from a third structure determination by powder diffractometry (SDPD) round robin are discussed. From the 175 potential participants having downloaded the powder data, nine sent a total of 12 solutions ( 8 and 4 for samples 1 and 2, respectively, a tetrahydrated calcium tartrate and a lanthanum tungstate). Participants used seven different computer programs for structure solution (ESPOIR, EXPO, FOX, PSSP, SHELXS, SUPERFLIP, and TOPAS), applying Patterson, direct methods, direct space methods, and charge flipping approach. It is concluded that solving a structure from powder data remains a challenge, at least one order of magnitude more difficult than solving a problem with similar complexity from single-crystal data. Nevertheless, a few more steps in the

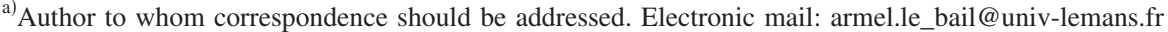


direction of increasing the SDPD rate of success were accomplished since the two previous round robins: this time, not only the computer program developers were successful but also some users. No result was obtained from crystal structure prediction experts. (C) 2009 International Centre for Diffraction Data. [DOI: 10.1154/1.3200881]

Key words: powder diffraction, crystal structure determination, round robin, blind test

\section{INTRODUCTION}

Two structure determinations by powder diffractometry (SDPD) round robins (RRs) were organized in 1998 and 2002 (Le Bail and Cranswick, 2001, 2003). In both cases, materials (raw powder diffraction patterns) were distributed worldwide on the internet and the competition was opened to all. The number of potential participants (counting the data downloads) was 70 for the SDPDRR-1, only two of them sent a solution to the second of two problems (one inorganic and one pharmaceutical). Both participants were the conceivers/developers of the computer programs they applied (DASH and CSD). The SDPDRR-2 was proposed in two steps, indexing and then structure solution. Again, only two participants completed the second step, sending the solutions for the first two of three samples (one inorganic, one organometallic, and a fullerene compound). And again, these two participants were the conceivers/developers of the computer programs (FOX and TOPAS). Because no external user of the structure solution computer programs could provide any solution, it was concluded that the SDPD of these compounds was not attainable in a routine manner. As a consequence of the one-dimensional character of powder diffraction data, inducing considerable overlap of diffraction peaks, the complexity of a problem is mainly dependent on two causes, instrumental (or instrumental and sample dependent if the crystallinity is low via contribution to the broadening) and structural. High instrumental resolution can reduce peak overlap problems, favouring the use of synchrotron radiation since more complex problems can in principle be solved. The number of degrees of freedom (DOFs) at the solution stage is the second parameter that determines the complexity of a SDPD problem. This DOF number will depend on the number of atoms in the asymmetric unit or on the number of independent molecules and torsion angles if the molecular geometry is known (one molecule corresponding to six DOFs, three positional and three orientational; one atom in general position corresponding to three DOFs). The effective number of DOF at the solving (sDOF) stage is the central value that we will consider here, being the smallest number of unknown parameters necessary to estimate the initial structural model that will allow for the completion and (Rietveld) refinement of the final crystal structure. At the refinement stage, rDOF can be defined, represented by the number of atomic coordinates which should be refined. The sDOF can be considerably smaller than the rDOF depending on the level of chemical knowledge about the sample which will determine the choice of the structure solution method (classical methods such as Patterson or direct methods or the direct space approach). We are now close to 1500 published structures determined from powder diffraction data, 200/ year. Since the previous SDPDRR-2 in 2002, many new computer programs appeared for the purpose of SDPD, and the access to them (academic or commercial) is also much broader. Recently, the charge flipping approach (Oszlányi and Sütö, 2004) was adapted to powder data (Baerlocher et al., 2007). Moreover, structure prediction has progressed after a series of blind tests (Day et al., 2005). It was thus considered timely to try to verify by a SDPDRR-3 if we are now closer to the expected "routine SDPD." Moreover it was explicitly requested by the Chairman of the IUCr Commission on Powder Diffraction: "It is a decade since Armel Le Bail and Lachlan Cranswick issued a challenge to the powder diffraction community to solve two crystal structures from powder diffraction data alone. Despite a generous time scale of around 6 weeks, there were less than a handful of correct solutions. Would the situation be different today? I think so-but I do have a number of caveats. (...) With all the diversity of methodologies presented in this newsletter, are we nearer to saying that structure determination from powder diffraction data is routine. My personal view is that for the general user, it is not. (...) Perhaps then, Armel and Lachlan, we will all be ready for another SDPD round robin." (David, 2007).

\section{SDPD}

The possibilities to completely solve complex structures from powder diffraction data alone are described in many review articles and a few recent books (David et al., 2002; Pecharsky and Zavalij, 2003; Clearfield et al., 2008; Dinnebier and Billinge, 2008). The topic is young since less than 300 published SDPDs were realized ten years ago and less than 2000 today (now running at 200/year). It is thus a quite small niche when compared to structure determination from single-crystal data ( $\sim 0000 /$ year), mainly gathered in the repositories of organic crystal structures, the Cambridge structural database (CSD) (Allen, 2002), and of inorganics (ICSD) (Belsky et al., 2002). However, during the last 20 years from several research teams, considerable efforts have been made in order to improve our abilities in that domain. For such a young topic, it is desirable from time to time to offer the community some problems to solve in order to compare the efficiency of various approaches and to provide guidelines to the users, as was frequently the case for the powder diffraction community in the past (surveys of crystallographic program packages, interlaboratory intercomparisons of procedures) or more recently to give a few references: the Rietveld RR (Hill and Cranswick, 1994), the Rietveld refinement guidelines (McCusker et al., 1999), the quantitative phase analysis RR (Madsen et al., 2001), the indexing (Bergmann et al., 2004), and the size strain RR (Balzar et al., 2004). Because SDPD attempts are either succeeding or failing, we do not expect to be able to provide many new and meaningful recommendations but at least the target is to show the state of the art, how experts may approach and eventually solve differently some typical and 


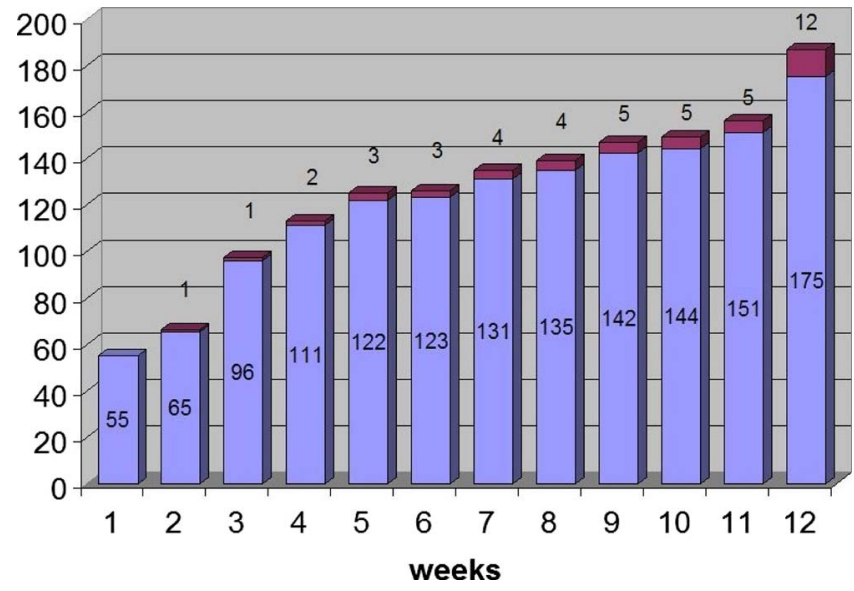

Figure 1. (Color online) Data downloads and solutions received along the 12-week duration (2008) of the round robin.

relatively difficult problems, using the same data. Forming an opinion by only reading the computer program manuals gives a relatively false impression that SDPD can be easily performed in a routine manner.

\section{ROUND-ROBIN ORGANIZATION, SAMPLES, AND TIMETABLE}

The SDPDRR-3 was proposed for two indexed powder patterns (similarly to the RR-1), a new tetrahydrated calcium tartrate polymorph and a lanthanum tungstate. Because so few solutions were obtained during the first two RRs, more time was allocated, exactly 3 months from February 1st to April 30, 2008 (Figure 1). The information was distributed worldwide through the SDPD and Rietveld mailing lists (having respectively more than 700 and 1000 subscribers), the sci.techniques.xtallography newsgroup, and personal electronic mails were sent to the conceivers/developers of SDPD computer programs and to the previous participants of the crystal structure prediction blind tests. A probably nonexhaustive list of published dedicated SDPD software from which structure solution could be expected for one or both samples is as follow (alphabetical order): DASH (David et al., 2006), EAGER (Harris et al., 1998), ENDEAVOUR (Putz et al.,

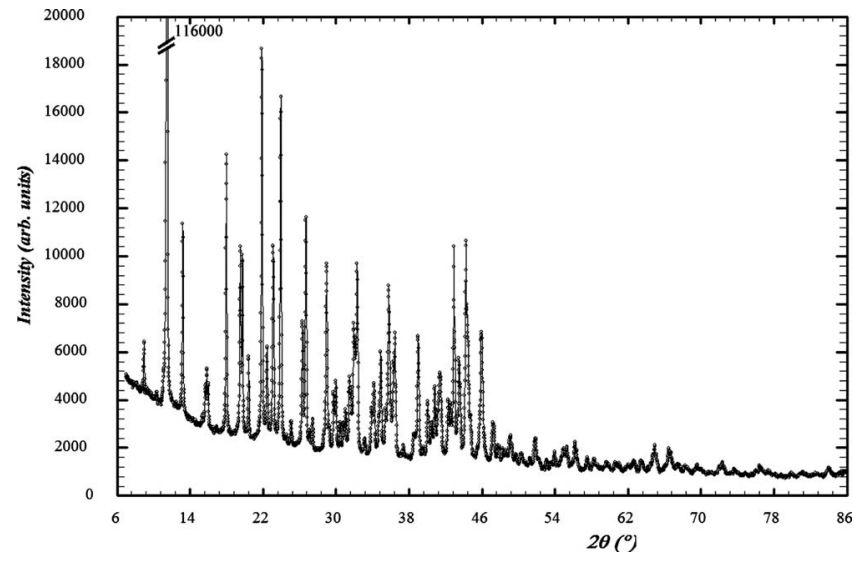

Figure 2. X-ray powder pattern for sample 1 (calcium tartrate tetrahydrate). The second reflection at low angle culminates at $\sim 116000$ counts.

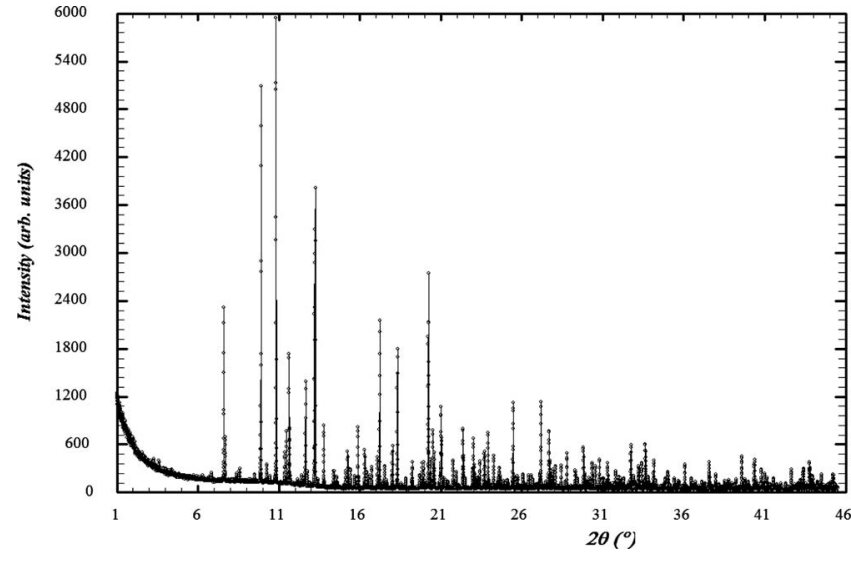

Figure 3. Synchrotron powder pattern for sample 2 (lanthanum tungstate).

1999), ESPOIR (Le Bail, 2001), EXPO (Altomare et al., 2004), FOX (Favre-Nicolin and Cerny, 2002), GEST (Feng and Dong, 2007), OCTOPUS (Harris et al., 1994), ORGANA (Brodski et al., 2005), POWDERSOLVE (Engel et al., 1999), PSSP (Stephens and Huq, 2002), SAFE (Brenner et al., 2002), SA (Andreev et al., 1997), SIMPEL (Jansen et al., 1993), SUPERFLIP (Palatinus and Chapuis, 2007), TOPAS (Coelho, 2000), and XLENS (Rius, 2004). A list of computer programs for the prediction of the packing of molecular structure, which could have been used for the structure solution of sample 1, can be found in Day et al., 2005. The powder patterns for the two samples were experimental, supplied in various standard formats (Figures 2-4). The participants were warned about the possibility of impurity presence as well as systematic zeropoint error or even some preferred orientation. The additional details provided are gathered in Table I.

For the new calcium tartrate tetrahydrate form, a CIF provided the tartrate molecular formula as established from two previous single-crystal structure determinations (Hawthorne et al., 1982; Boese and Heinemann, 1993). For the lanthanum tungstate, the formula and cell were provided according to the published literature mentioning composition variations. If the cell parameters given for sample 1 could allow directly for a Pawley (1981) or Le Bail (2005) fit, this was not the case for sample 2. Moreover, the space groups were not defined, either $P 1$ or $P-1$ for sample 1 , whereas the list of possibilities was longer for sample 2. Those looking

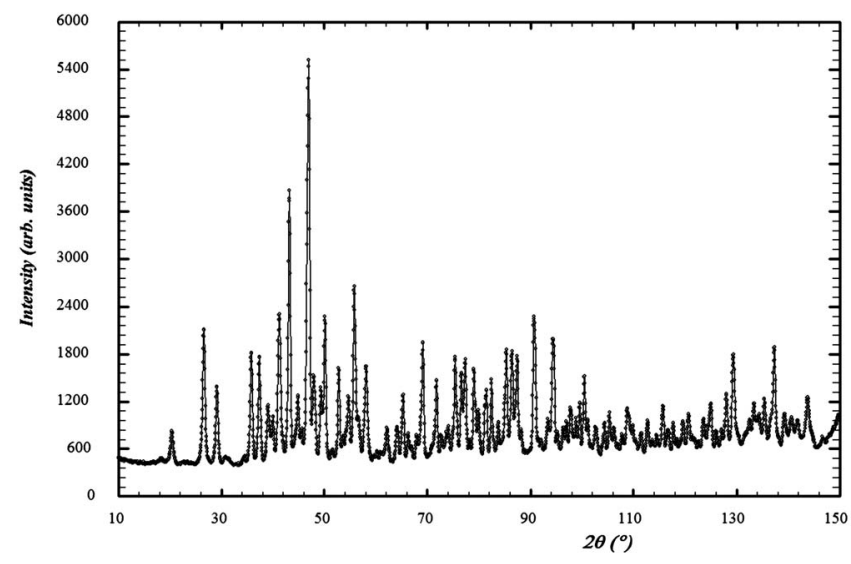

Figure 4. Neutron powder pattern for sample 2 (lanthanum tungstate). 
TABLE I. Data provided for samples 1 and 2 .

\begin{tabular}{|c|c|c|c|c|}
\hline & & & Sample 1 & Sample 2 \\
\hline Probable formula & & & $\mathrm{CaC}_{4} \mathrm{H}_{4} \mathrm{O}_{6} \cdot 4 \mathrm{H}_{2} \mathrm{O}$ & $\mathrm{La}_{14} \mathrm{~W}_{8} \mathrm{O}_{45}$ or $\mathrm{La}_{8} \mathrm{~W}_{5} \mathrm{O}_{27}$ \\
\hline \multirow[t]{6}{*}{ Cell parameters } & $(\AA)$ & $a=$ & 8.222 & 9.039 \\
\hline & & $b=$ & 10.437 & 9.039 \\
\hline & & $c=$ & 6.249 & 32.60 to 33.65 \\
\hline & $(\mathrm{deg})$ & $\alpha=$ & 105.97 & 90 \\
\hline & & $\beta=$ & 107.51 & 90 \\
\hline & & $\gamma=$ & 94.94 & 120 \\
\hline Symmetry & & & Triclinic & Hexagonal \\
\hline ICDD-JCPDS cards & & & None & 032-0502 and 032-0503 \\
\hline \multirow[t]{3}{*}{ Geometry } & & & Reflection & Transmission \\
\hline & & & Laboratory instrument & Synchrotron/neutron \\
\hline & & & Bragg Brentano & Capillary/vanadium can \\
\hline Instrument & & & PANalytical & ESRF BM01/ILL D2B \\
\hline Wavelength & & & $\mathrm{Cu} K \alpha$ & $0.60044 / 1.5944(\AA)$ \\
\hline
\end{tabular}

accurately at the publications mentioned in the ICDD-JCPDS cards could have found more details, but they were contradictory: "possible space groups $P 6_{3} / m m c, P 6_{3} n m c$, and $P-62 c$," favouring the centrosymmetrical group (negative result at the generation of second harmonic)" (Yanovskii and Voronkova, 1975); "hexagonal with $R-62 c$ space group" (Kovalevsky et al., 1999). Table II provides the sDOF and rDOF corresponding to the various samples of the SDPDRR-1, 2, and 3. However, they are estimated as if the final structure and space group were known by the participants, which was not always the case.

\section{CRYSTAL STRUCTURES AS SOLVED BY THE ORGANIZERS}

\section{A. Sample 1: Calcium tartrate tetrahydrate}

Large crystals (100 to $200 \mu \mathrm{m}$ ) were extracted from rat kidney. The chemical analysis suggested a hydrated calcium tartrate. The crystal structure determination revealed a new tetrahydrated form. Crystals were found in massive intergrowths and first resisted to the characterization attempts due to the difficulties to separate a real single crystal. Indexing in a triclinic cell was realized from powder diffraction data by

TABLE II. Supposing the space group and structure known, minimal number of degrees of freedom at the structure solution (sDOF) stage from X-ray data for various methods, and total number of refinable (rDOF) atomic coordinates (non-H atoms). DM: direct methods, Patt: Patterson method, DS: direct space method, References: SDPDRR-1, samples 1 (Zhu et al., 1999) and 2 (Clegg and Teat, 2000); SDPDRR-2 samples 1 (Adil et al., 2007) and 2 (Le Bail, 2003); and SDPDRR-3 samples 1 (Le Bail et al., 2009) and 2 (Chambrier et al., 2009).

\begin{tabular}{|c|c|c|c|}
\hline & SDPDRR-1 & SDPDRR-2 & SDPDRR-3 \\
\hline & Sample 1 & Sample 1 & Sample 1 \\
\hline & Sample 2 & Sample 2 & Sample 2 \\
\hline \multirow[t]{2}{*}{ Chemical formula } & {$\left[\mathrm{Co}\left(\mathrm{NH}_{3}\right)_{5} \mathrm{CO}_{3}\right] \mathrm{NO}_{3} \cdot \mathrm{H}_{2} \mathrm{O}$} & $\mathrm{Al}_{2} \mathrm{~F}_{10}\left[\mathrm{C}_{6} \mathrm{~N}_{4} \mathrm{H}_{20}\right]$ & $\mathrm{CaC}_{4} \mathrm{H}_{4} \mathrm{O}_{6} \cdot 4 \mathrm{H}_{2} \mathrm{O}$ \\
\hline & $\mathrm{C}_{22} \mathrm{H}_{24} \mathrm{~N}_{2} \mathrm{O}_{8} \mathrm{HCl}$ & $\mathrm{Sr}_{5} \mathrm{~V}_{3}\left(\mathrm{~F} / \mathrm{O} / \mathrm{H}_{2} \mathrm{O}\right)_{22}$ & $\mathrm{La}_{18} \mathrm{~W}_{10} \mathrm{O}_{57}$ \\
\hline \multirow[t]{2}{*}{ Space group } & $P 2_{1}$ & $P 2 / c$ & $P-1$ \\
\hline & $P 2_{1} 2_{1} 2_{1}$ & $P 2_{1} / c$ & $P-62 c$ \\
\hline \multirow[t]{2}{*}{$Z$} & 2 & 2 & 2 \\
\hline & 4 & 4 & 2 \\
\hline Total independent & 15 & 12 & 15 \\
\hline non-H & 33 & 30 & 20 \\
\hline \multicolumn{4}{|l|}{ Sites to find by } \\
\hline \multirow[t]{2}{*}{ DM/Patt } & $\sim 10$ & $\sim 10$ & $\sim 10$ to 15 \\
\hline & $\sim 20$ & $\sim 15$ & $6 \mathrm{~W}+4 \mathrm{La}$ \\
\hline sDOF DS: & $6 \times 3+3=21$ & $6 \times 3=18$ & $6+5 \times 3=21$ \\
\hline mol+atoms & $6+3=9$ & $6 \times 8=48$ & $10 \times 3=30$ \\
\hline \multirow[t]{2}{*}{ rDOF } & 44 & 30 & 45 \\
\hline & 99 & 90 & 43 \\
\hline \multirow[t]{2}{*}{ Data quality } & Low & Low & Low \\
\hline & Medium & High & High \\
\hline
\end{tabular}




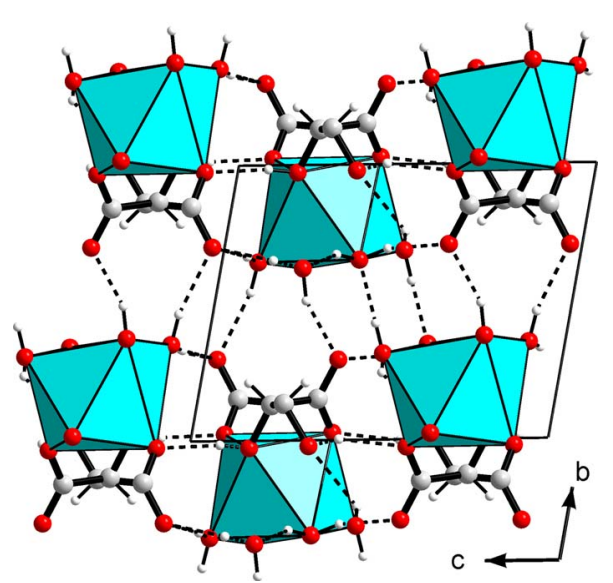

Figure 5. (Color online) Calcium tartrate tetrahydrated crystal structure drawing.

using the MCMAILLE software (Le Bail, 2004). The structure was solved from the powder data by direct space method using the ESPOIR software (Le Bail, 2001) applied to intensities extracted by the Le Bail (2005) method in space group $P-1$. The tartrate molecule was rotated and translated together with the calcium and remaining water oxygen atoms up to find an optimum by a Monte Carlo process. From these convincing results, more efforts were taken with the data collected from a selected "single crystal," producing a final refinement of much higher quality than from the powder data; this in spite of the relatively high $R$ factor due to peak overlapping from several intergrown domains (Figure 5) (Le Bail et al., 2009).

\section{B. Sample 2: Lanthanum tungstate}

In a previous study (Yanovskii and Voronkova, 1975) (from single-crystal data though the structure determination was not completed because it was not possible to obtain good crystals), the commonest six-layered polytype was said to belong to the space group $P 6_{3} / m m c$ (no piezoeffect detected) with cell parameters $a=9.04(1) \AA$ and $c=32.60$ to $33.65 \AA$ depending on the composition of the crystal. This cell was confirmed here by a satisfying whole powder pattern fit by using the Le Bail method through the FULLPROF software (Rodriguez-Carvajal, 1993). The extracted intensities from the synchrotron powder pattern were then used for attempting the structure solution by direct space methods as embedded in the ESPOIR software, searching for the heavy W and La independent atoms by a Monte Carlo process. Nothing better than $R_{\mathrm{p}}>35 \%$ could be obtained during various tests in the $P 6_{3} / m m c$ or $P 6_{3} m c$ space groups. Direct or Patterson methods failed as well to provide a satisfying starting model. Then, instead of trying directly the other possible space groups $(P-62 c, P-31 c$, and $P 31 c)$, the search for a solution was made in the $c / 6$ subcell in spite of the fact that very intense reflections had to be excluded (scaling the most intense 206 at $I=100$, the 207 is at $I=13$, and the 217 is at $I=14)$. Trying various space groups without extinction, a promising model leading to $R_{\mathrm{p}}=22 \%$ on 220 remaining peaks was finally obtained from the ESPOIR software in the $P-62 m$ space group, corresponding to a $\mathrm{La} / \mathrm{W}=2$ ratio $\left(\mathrm{La}_{2} \mathrm{WO}_{6}\right.$ formula). No extension of that model in the large

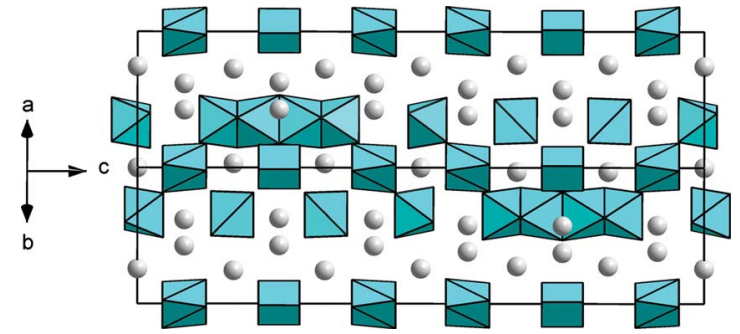

Figure 6. (Color online) Lanthanum tungstate crystal structure drawing.

cell could be obtained in the $P 6_{3} / m m c$ or $P 6_{3} m c$ space groups. Then the other space groups compatible with the $h h-2 h l, l=2 n$ reflection condition were examined $(P-62 c$, $P-31 c$, and $P 31 c$ ). The small initial model could be finally extended in the large cell by using the acentric space groups, for instance with four $\mathrm{La}$ and five $\mathrm{W}$ independent atom sites in the general or special positions of $P-62 c$. Introducing these atomic coordinates into a Rietveld (1969) refinement led then to $R_{\mathrm{B}}=19.7 \%$ and $R_{\mathrm{F}}=11.1 \%$ when the thermal parameters were refined (most having negative values because of the absence of absorption correction at this stage). From a Fourier difference map, an additional $\mathrm{W}$ atom site was detected as well as all the oxygen atoms in ten independent sites. Further refinements suggested that this new W site had to be half occupied, leading to the $\mathrm{La}_{18} \mathrm{~W}_{10} \mathrm{O}_{57}$ formula with $Z=2$. A part of the $\mathrm{W}$ atoms are found in octahedral coordination but the majority of them are in an unusual trigonal prismatic coordination (Figure 6). This unusual trigonal prismatic coordination was previously observed for the $\mathrm{WO}_{6}$ group in the $\mathrm{X}$-ray studies of $\mathrm{Pr}_{3} \mathrm{WO}_{6} \mathrm{Cl}_{3}$ (Polyanskaya et al., 1969) and $\mathrm{La}_{3} \mathrm{WO}_{6} \mathrm{Cl}_{3}$ (Brixner et al., 1982), the latter structure being then confirmed from neutron powder diffraction data (Parise and Brixner, 1983). Tests in order to see if reducing the symmetry would allow the half occupied W site to become fully ordered were made in $P 31 \mathrm{C}$ and in various subgroups of $P-62 c$ and $P 31 c$ (Ama2, Cc) with no convincing result: the number of atomic coordinates to be refined becoming prohibitive (Chambrier et al., 2009).

\section{CRYSTAL STRUCTURES AS SOLVED BY THE PARTICIPANTS}

The results for the structure solution step are summarized in Table III (complete reports are available as supplementary materials (http://www.cristal.org/SDPDRR3/). From the 175 potential participants having downloaded the data, nine sent a total of 12 solutions ( 8 and 4 for samples 1 and 2, respectively). They used seven different computer programs for structure solution. This third round robin received more results compared to first and second round robins and for the first time, contributions were also obtained from nonsoftware developers. This implies that solving structures from powder diffraction data is becoming more accessible to nonexperts compared to previous round robins.

The person-time required for solving from powder data a crystal structure can be almost as short as for single-crystal data, providing that the correct solution is recognized at the first try. Computing time is in general longer for the programs working in direct space methods. 


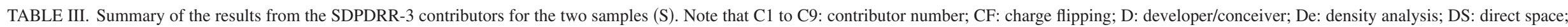

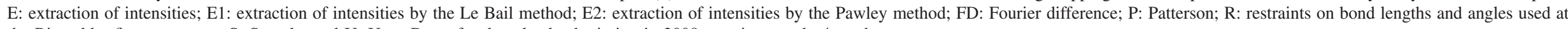
the Rietveld refinement stage; S: Sample; and U: User. Dates for download submission in 2008 are given as day/month

\begin{tabular}{|c|c|c|c|c|c|c|}
\hline Contributor (user or developer) & $\mathrm{S}$ & Dates for download submission & Programs used & Solved with & Rietveld software & Comments \\
\hline $\begin{array}{l}\mathrm{C} 1 \\
(\mathrm{U})\end{array}$ & 1 & $1 / 2$ to $8 / 2$ & $\begin{array}{c}\text { GSAS(E1) } \\
\text { SHELXS } \\
\text { SIR2002 } \\
\text { EXPO } \\
\text { FOX }\end{array}$ & FOX(DS) & GSAS(R) & $\begin{array}{l}\text { SG: }-1 \text {. A few different attempts. (1) Tartrate treated as } \\
\text { a molecule, calcium, and four oxygen atoms all treated } \\
\text { independently of each other; DOF: } 24 \text {, torsions } 3 .(2) \\
\text { Only with two or three oxygen atoms bonded to calcium } \\
\text { atoms; DOF: } 18 \text {, torsions 3. (3) as (1) with more than } \\
\text { four not bonded oxygen atoms; DOF: around } 30 \text {, } \\
\text { torsions 3. This tartrate is a racemate. Sample } 2 \text { declared } \\
\text { solvable but not tried. }\end{array}$ \\
\hline
\end{tabular}

$22 / 2$ to $24 / 2$

JANA2000(E)

SUPERFLIP

$\operatorname{EDMA}(\mathrm{De})$
$14 / 2$ to $3 / 4$

$28 / 2$ to $20 / 3$
$14 / 2$ to $5 / 3$

TOPAS

TOPAS(DS)

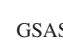

$\operatorname{TOPAS}(\mathrm{E})$

GSAS(E)

$\operatorname{SHELXS}(\mathrm{P})$

SHELXL(FD)

FORCITE
SUPERFLIP $(\mathrm{CF}) \quad$ JANA2000

SG: $P-62 c$. Ten atoms located (all $\mathrm{La}$ and $\mathrm{W}$ positions), then all oxygen atoms located by a Fourier difference synthesis performed after a Rietveld refinement. One La changed into a W half occupied. Symmetry $-62 c$ established by the "derive symmetry" option of SUPERFLIP. The whole process took about $2 \mathrm{~h}$.

SG: $P-1$. A $\mathrm{CaC}_{4} \mathrm{O}_{6} \mathrm{H}_{2}$ unit was taken from one of the single-crystal structures supplied (six DOFs). The

torsional angle around the tartrate central C-C bond was treated as an additional DOF. Four $\mathrm{O}$ atoms were also placed in the unit cell as independent entities, giving 12 additional DOF (19 total). When we were confident we had found the solution with lowest $R$ value, we also released all other torsional angles as well as a bond length and a bond angle that defined the position of $\mathrm{Ca}$ with respect to the tartrate moiety.

SG: $P-62 c$. Charge flipping (SUPERFLIP) to locate the heavy atom and direct space method (TOPAS) to locate the $\mathrm{O}$ atoms (no Fourier difference).

SG: $P$-1. Overlapping peaks were filtered (keeping 150 of 800 after extraction. Patterson procedure using SHELXS allowed to recognize $\mathrm{Ca}$ atoms. One of the $\mathrm{COO}$ groups was located in a series of Fourier syntheses using different subsets of the originally extracted Fobs's. Then the first Rietveld refinement was performed revealing the water oxygen atoms around $\mathrm{Ca}$. Positions of $\mathrm{H}$ atom from geometry optimization with molecular mechanics module forcite (Material Studio). 
TABLE III. (Continued.)

\begin{tabular}{|c|c|c|c|c|c|c|}
\hline Contributor (user or developer) & $\mathrm{S}$ & Dates for download submission & Programs used & Solved with & Rietveld software & Comments \\
\hline (U) & 1 & $2 / 2$ to $21 / 4$ & FOX & FOx(DS) & GSAS & $\begin{array}{l}\text { SG: } P-1 \text {. Started as } Z \text { matrix from Pb-tartrate example. Start } \\
\text { with one rigid body tartrate molecule plus five free atoms: } \\
1 \mathrm{Ca} \text { and } 4 \mathrm{O} \text {. Later on: release } 11 \text { torsion angles one by one } \\
\text { within window of } 10^{\circ} \text { around starting model angle. Next } Z \\
\text { matrix converted to molecule description for finding final } \\
\text { solution. }\end{array}$ \\
\hline \multirow{3}{*}{$\begin{array}{l}\text { C6 } \\
\text { (D) }\end{array}$} & 2 & $2 / 2$ to $21 / 4$ & FOX & FOX(DS) & GSAS & $\begin{array}{l}\text { SG: } C 2 \mathrm{~cm} \text {. Started with set of } \mathrm{La} \text { atoms and } \mathrm{WO}_{6} \text { octahedra. } \\
\text { Fourier map shows missing heavy atoms. FOX merges atoms } \\
\text { when too many atoms have been entered. Sometimes La } \\
\text { atoms and } \mathrm{W} \text { octahedra had to be interchanged. Initially only } \\
\text { the X-ray pattern was used to find heavy atom positions. } \\
\text { Later on the neutron pattern was added to position O atoms. } \\
\text { The final Fox solution had } 11 \mathrm{La} \text { atoms and } 5 \mathrm{~W} \text { octahedra. }\end{array}$ \\
\hline & 1 & $2 / 2$ to $29 / 4$ & $\begin{array}{l}\text { FULLPROF(E1) } \\
\text { FOX }\end{array}$ & FOX(DS) & TOPAS & $\begin{array}{l}\text { SG: } P-1.1 \text { semirigid molecule } 2 R, 3 R \mathrm{C}_{4} \mathrm{H}_{4} \mathrm{O}_{6} \text { with internal } \\
\text { DOF and restraints as used in FOX. Four rigid molecules } \\
\mathrm{H}_{2} \mathrm{O} \text {. One free atom of Ca. A total of } 33 \text { DOFs + internal DOF } \\
\text { of the } \mathrm{C}_{4} \mathrm{H}_{4} \mathrm{O}_{6} \text { molecule. }\end{array}$ \\
\hline & 2 & $2 / 2$ to $29 / 4$ & FULLPROF(E1) & FOx(DS) & TOPAS & $\begin{array}{l}\text { SG: } P 31 c .6 \text { free atoms of } \mathrm{La}, 9 \text { free atoms of } \mathrm{W}, 18 \text { free } \\
\text { atoms of } \mathrm{O}, 1 \text { octahedron } \mathrm{WO}_{6} \text {. A total of } 105 \text { DOFs. Both } \\
\text { data sets used jointly for structure solution and refinement. }\end{array}$ \\
\hline (D) & 1 & $7 / 2$ to $30 / 4$ & EXPO200X & EXPO200X & EXPO200X & $\begin{array}{l}\text { SG: P-1. Solved by direct method and simulated annealing } \\
\text { DM: whole structure (non-H atoms) recognized at the third } \\
\text { phasing trial. SA: Six independent molecules/atoms: one } \\
\text { tartrate, four water molecules, one Ca atom. Total number of } \\
\text { DOFs }=38 \text { ( } 33 \text { external DOFs and } 5 \text { torsion angles). Sample } 2 \\
\text { declared solvable but probably additional chemical } \\
\text { information is needed. }\end{array}$ \\
\hline $\begin{array}{l}\mathrm{C} 8 \\
(\mathrm{U})\end{array}$ & 1 & $4 / 2$ to $30 / 4$ & $\begin{array}{l}\text { FULLPROF }(\text { E1) } \\
\text { ESPOIR }\end{array}$ & ESPOIR(DS) & FULLPROF & $\begin{array}{l}\text { SG: } P-1 \text {. One } \mathrm{CaO}_{8} \text { polyhedron, a } \mathrm{C}_{4} \text { molecule with free } \\
\text { torsion angle and } 2 \mathrm{O} \text { atoms. Best solution with } R=0.205 \text { at } \\
\text { test } 91 .\end{array}$ \\
\hline (D) & 1 & $20 / 4$ to $1 / 5$ & TOPAS(E2) & PSSP(DS) & TOPAS & $\begin{array}{l}\text { SG: } P 1 \text {. Based on description of the sample as tartrate (rather } \\
\text { than mesotartrate), space group } P 1 \text { was selected. Two } \\
\text { independent tartrates, each with Ca tethered in a likely } \\
\text { location to two oxygen atoms. eight independent oxygen } \\
\text { atoms. The Ca and carboxyl torsions were varied over a } \\
\text { limited range relative to planar. So each Ca tartrate was } \\
\text { described by three translations, three rotations, and three } \\
\text { torsions. Eight independent oxygens have three translations } \\
\text { each for a grand total of } 42 \text { parameters. Questionable } \\
\text { refinement was ascribed to low resolution data. Sample } 2 \text { not } \\
\text { really tried. }\end{array}$ \\
\hline
\end{tabular}




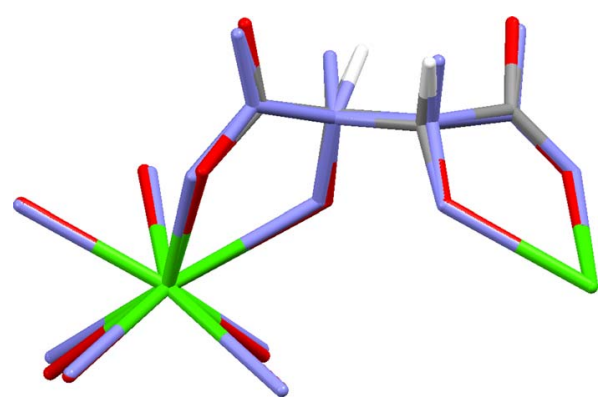

Figure 7. (Color online) Projection along the $c$ axis of the superposition of the tartrate structure as obtained before and after Rietveld refinement (contributor $\mathrm{C} 1)$.

The fact is that participants may end in multiple solutions $(P 1$ or $P-1$ for sample 1 and $P-62 c, P 31 c$, or $C 2 \mathrm{~cm}$ for sample 2). We can only suppose that these differences would have vanished at the Rietveld structure refinement after more efforts and symmetry-checking ultimate stages (Spek, 2003), which were not included into the SDPDRR-3 targets and so not always realized (this was not a Rietveld round robin). For instance, applying the PLATON symmetry check to the $P 31 \mathrm{c}$ model suggests that it fits at $91 \%$ in $P-62 c$ (the disordered $\mathrm{W}$ atom in $P-62 c$ can be ordered in $P 31 c$ ); for the $C 2 \mathrm{~cm}$ description, PLATON suggests the hexagonal symmetry with $\gamma$ $=119.98^{\circ}$; for the $P 1$ tartrate description, PLATON does not find the inversion center, saying "no obvious space group change needed." For these reasons, no metrics will be presented for comparing the structure models with the "known" solutions. Moreover, if the tartrate structure, finally refined from single-crystal data, can be considered as hardly disputable, the lanthanum tungstate structure could be certainly discussed, and some participants could well have tried to publish their own results sometimes differing a bit from the structure determined by the organizers, and even some modern crystallographers would possibly have applied some four-dimensional algorithm to this disordered and clearly modulated (but commensurable) structure. Anyway, given the low level of success, it appears too early to propose a round robin which would address the accuracy issue, comparing the models obtained at the solution stage with the final structures. Nevertheless, when available from the participants, the comparison between the atomic coordinates at the structure solution and at the Rietveld stage shows little differences. For instance in the case of the tartrate (participant C1, see Table III) on a plot of the before/after refinement coordinates (Figure 7), the largest discrepancy in position is observed for the $\mathrm{H}$ atoms involved in $\mathrm{C}-\mathrm{H}$ bonds (other $\mathrm{H}$ atoms not located). This round robin is limited to give answers to simple questions "can this be done?" or "is it routine?" Moreover, if the minimal model allowing then to refine and complete the structure in the calcium tartrate case is close to $80 \%$ of the atomic positions (including $\mathrm{Ca}$, excluding $\mathrm{H}$ ), it is limited to the finding of the heavy atoms (W, La) in the tungstate case from the synchrotron data even if some computer programs are able to locate most of the oxygen atoms altogether by combining the synchrotron and the neutron data.

\section{DISCUSSION AND CONCLUSIONS}

One should note that for crystallographers, either from powder or single-crystal data, structure solution is realized by expert algorithms embedded in computer programs not by human brains. Human intervention is limited to the choice of the computer program (looking adapted to the problem type) and to the preparation of the data and instructions required by the program. The question why 166 of the 175 participants $(\sim 95 \%)$ did not sent any result may be answered in a simple way: most of the powder diffraction computer programs for structure solution have not attained the level of automatism of the single-crystal software which beneficiate generally of high-quality three-dimensional intensity data. Very probably, the same problems as those presented in this round robin would have been solved by $>95 \%$ of the participants from single-crystal data. The monodimensionality of a powder pattern implies that this routine character of a single-crystal approach (unless twinning or other difficulties) is lost because the solution is much less easily recognized, consequently to the data overlapping, and even the recording of an optimum data set requires special care. We could first advice to the software developers to include more efficiency and user friendliness in their computer programs than was done up to now. Second the advice to the powder diffraction expert is to increase his training level in crystallography and this would perhaps improve the current poor SDPD success rate. The SDPDRR-3 establishes that when properly applied by capable users, a variety of algorithmic methods is effective for solving structures from powder diffraction data as provided by round-robin organizers. In the previous SDPDRR-1 and SDPDRR-2, software developers were the only contributors. In comparison with previous RR, solving round-robin structures was found to be feasible by users of existing packages, though developers of structure solving packages predominated (some being able to find a solution in a few hours using their own software). This round robin does not pretend to the generalization to any SDPD from a sample of two structures, and there is no new scientific knowledge to extract from it. It just shows that more science or more user friendliness has to be included in SDPD software if one expects to see more (complex) crystal structures solved by scientists moderately trained in crystallography interested in such problems.

Adil, K., Le Bail, A., Dujardin, G., and Maisonneuve, V. (2007). "A new 1D hybrid fluoroaluminate templated by an original tetramine," Polyhedron 26, 2493-2497.

Allen, F. H. (2002). "The Cambridge structural database: A quarter of a million crystal structures and rising," Acta Crystallogr., Sect. B: Struct. Sci. 58, 380-388.

Altomare, A., Caliandro, R., Camalli, M., Cuocci, C., Giacovazzo, C., Moliterni, A. G. G., and Rizzi, R. (2004). "Automatic structure determination from powder data with EXPO2004," J. Appl. Crystallogr. 37, 10251028.

Andreev, Y. G., Lightfoot, P., and Bruce, P. G. (1997). "A general Monte Carlo approach to structure solution from powder-diffraction data: Application to poly(ethylene oxide $)_{3}: \mathrm{LiN}\left(\mathrm{SO}_{2} \mathrm{CF}_{3}\right)_{2}$, J. Appl. Crystallogr. 30, 294-305.

Baerlocher, Ch., McCusker, L., and Palatinus, L. (2007). "Charge flipping combined with histogram matching to solve complex crystal structures from powder diffraction data," Z. Kristallogr. 222, 47-53.

Balzar, D., Audebrand, N., Daymond, M. R., Fitch, A., Hewat, A., Langford, J. I., Le Bail, A., Louër, D., Masson, O., McCowan, C. N., Popa, N. C., Stephens, P. W., and Toby, B. H. (2004). "Size-strain linebroadening analysis of the ceria round-robin sample," J. Appl. Crystal- 
logr. 37, 911-924.

Belsky, A., Hellenbrandt, M., Karen, V. L., and Luksch, P. (2002). "New developments in the inorganic crystal structure database (ICSD): Accessibility in support of materials research and design," Acta Crystallogr., Sect. B: Struct. Sci. 58, 364-369.

Bergmann, J., Le Bail, A., Shirley, R., and Zlokazov, V. (2004). "Renewed interest in powder diffraction data indexing," Z. Kristallogr. 219, 783790.

Boese, R. and Heinemann, O. (1993). "Crystal-structure of calcium tartrate tetrahydrate, $\mathrm{C}_{4} \mathrm{H}_{4} \mathrm{O}_{6} \mathrm{Ca}\left(\mathrm{H}_{2} \mathrm{O}\right)_{4}$," Z. Kristallogr. 205, 348-349.

Brenner, S., McCusker, L. B., and Baerlocher, C. (2002). "The application of structure envelopes in structure determination from powder diffraction data," J. Appl. Crystallogr. 35, 243-252.

Brixner, L. H., Chen, H. Y., and Foris, C. M. (1982). "Structure and luminescence of some rare-earth halotungstates of the type $\mathrm{Ln}_{3} \mathrm{WO}_{6} \mathrm{Cl}_{3}$," J. Solid State Chem. 44, 99-107.

Brodski, V., Peschar, R., and Schenk, H. (2005). "ORgana: A program package for structure determination from powder diffraction data by directspace methods," J. Appl. Crystallogr. 38, 688-693.

Chambrier, M. H., Le Bail, A., Kodjikian, S., Suard, E., and Goutenoire, F. (2009). "Structure determination of $\mathrm{La}_{18} \mathrm{~W}_{10} \mathrm{O}_{57}$," Inorg. Chem. 48, 6566-6572.

Clearfield, A., Reibenspies, J. H., and Bhuvanesh, N. (2008). Principles and Applications of Powder Diffraction (Blackwell, Oxford).

Clegg, W. and Teat, S. J. (2000). "Tetracycline hydrochloride: A synchrotron microcrystal study," Acta Crystallogr., Sect. C: Cryst. Struct. Commun. 56, 1343-1345.

Coelho, A. A. (2000). "Whole-profile structure solution from powder diffraction data using simulated annealing," J. Appl. Crystallogr. 33, 899908.

David, W. I. F. (2007). "CPD Chairman's Message," Commission on Powder Diffraction IUCr Newsletter, Vol. 35, p. 2, (http://www.iucr.org/ resources/commissions/powder-diffraction/newsletter).

David, W. I. F., Shankland, K., McCusker, L. L., and Baerlocher, Ch. (2002). Structure Determination from Powder Diffraction Data (Oxford University Press, Oxford).

David, W. I. F., Shankland, K., van de Streek, J., Pidcock, E., Motherwell, W. D. M., and Cole, J. C. (2006). "DASH: A program for crystal structure determination from powder diffraction data," J. Appl. Crystallogr. 39, 910-915.

Day, G. M., Motherwell, W. D. S., Ammon, H. L., Boerrigter, S. X. M., Della Valle, R. G., Venuti, E., Dzyabchenko, A., Dunitz, J. D., Schweizer, B. P., van Eijck, B. P., Erk, P., Facelli, J. C., Bazterra, V. E., Ferraro, M. B., Hofmann, D. W. M., Leusen, F. J. J., Liang, C., Pantelides, C. C., Karamertzanis, P. G., Price, S. L., Lewis, T. C., Nowell, H., Torrisi, A., Scheraga, H. A., Arnautova, Y. A., Schmidt, M. U., and Verwer, P. (2005). "A third blind test of crystal structure prediction," Acta Crystallogr., Sect. B: Struct. Sci. 61, 511-527.

Dinnebier, R. E. and Billinge, S. J. L. (2008). Powder Diffraction-Theory and Practice (RSC, Cambridge).

Engel, G. E., Wilke, S., Konig, O., Harris, K. D. M., and Leusen, F. J. J. (1999). "POWDERSOLVE: A complete package for crystal structure solution from powder diffraction patterns," J. Appl. Crystallogr. 32, 1169-1179.

Favre-Nicolin, V. and Cerny, R. (2002). "Fox: Free objects for crystallography: A modular approach to $a b$ initio structure determination from powder diffraction," J. Appl. Crystallogr. 35, 734-743.

Feng, Z. J. and Dong, C. (2007). "GEST: A program for structure determination from powder diffraction data using a genetic algorithm," J. Appl. Crystallogr. 40, 583-588.

Harris, K. D. M., Johnston, R. L., and Kariuki, B. M. (1998). "The genetic algorithm: Foundations and applications in structure solution from powder diffraction data," Acta Crystallogr., Sect. A: Found. Crystallogr. 54, 632-645.

Harris, K. D. M., Tremayne, M., Lightfoot, P., and Bruce, P. G. (1994). "Crystal-structure determination from powder diffraction data by MonteCarlo methods," J. Am. Chem. Soc. 116, 3543-3547.

Hawthorne, F. C., Borys, I., and Ferguson, R. B. (1982). "Structure of calcium tartrate tetrahydrate," Acta Crystallogr., Sect. B: Struct. Crystallogr. Cryst. Chem. 38, 2461-2463.

Hill, R. J. and Cranswick, L. M. D. (1994). "International Union of Crys- tallography. Commission on Powder Diffraction. Rietveld refinement round robin. II. Analysis of monoclinic $\mathrm{ZrO}_{2}$," J. Appl. Crystallogr. 27, 802-844.

Jansen, J., Peschar, R., and Schenk, H. (1993). "Application of directmethods to powder data-A weighting scheme for intensities in the optimal symbolic addition program SIMPEL88," Z. Kristallogr. 206, 33-43.

Kovalevsky, A. V., Kharton, V. V., and Naumovich, E. N. (1999). "Oxygen ion conductivity of hexagonal $\mathrm{La}_{2} \mathrm{~W}_{1.25} \mathrm{O}_{6.75}$," Mater. Lett. 38, 300-304.

Le Bail, A. (2001). "ESPOIR: A program for solving structures by Monte Carlo analysis of powder diffraction data," Mater. Sci. Forum 378-381, 65-70.

Le Bail, A. (2003). COD1000005-http://www.crystallography.net/

Le Bail, A. (2004). "Monte Carlo indexing with mCMallle," Powder Diffr. 19, 249-254.

Le Bail, A. (2005). "Whole powder pattern decomposition methods and applications: A retrospection," Powder Diffr. 20, 316-326.

Le Bail, A., Bazin, D., Daudon, M., Brochot, A., Robbez-Masson, V., and Maisonneuve, V. (2009). "Racemic calcium tartrate tetrahydrate (formII) in rat urinary stones," Acta Crystallogr., Sect. B: Struct. Sci. 65, 350-354.

Le Bail, A. and Cranswick, L. M. D. (2001). "Revisiting the 1998 SDPD round robin," Commission on Powder Diffraction IUCr Newsletter, Vol. 25, pp. 7-9 (http://www.iucr.org/resources/commissions/powderdiffraction/newsletter).

Le Bail, A. and Cranswick, L. M. D. (2003). "SDPD Round Robin 2002 results," Commission on Powder Diffraction IUCr Newsletter, Vol. 29, pp. 31-34 (http://www.iucr.org/resources/commissions/powderdiffraction/newsletter).

Madsen, I. C., Scarlett, N. V. Y., Cranswick, L. M. D., and Lwin, T. (2001). "Outcomes of the International Union of Crystallography Commission on Powder diffraction round robin on quantitative phase analysis: Samples $1 a$ to $1 h$," J. Appl. Crystallogr. 34, 409-426.

McCusker, L. B., Von Dreele, R. B., Cox, D. E., Louër, D., and Scardi, P. (1999). "Rietveld refinement guidelines," J. Appl. Crystallogr. 32, 3650.

Oszlányi, G. and Sütô, A. (2004). "Ab initio structure solution by charge flipping," Acta Crystallogr., Sect. A: Found. Crystallogr. 60, 134-141.

Palatinus, L. and Chapuis, G. (2007). "SUPERFLIP: A computer program for the solution of crystal structures by charge flipping in arbitrary dimensions," J. Appl. Crystallogr. 40, 786-790.

Parise, J. B. and Brixner, L. H. (1983). "Refinement of the structure of trilanthanum trichlorohexaoxotungstate, $\mathrm{La}_{3} \mathrm{WO}_{6} \mathrm{Cl}_{3}$, from neutron powder diffraction data," Acta Crystallogr., Sect. C: Cryst. Struct. Commun. 39, 1326-1328.

Pawley, G. S. (1981). "Unit-cell refinement from powder diffraction scans," J. Appl. Crystallogr. 14, 357-361.

Pecharsky, V. K. and Zavalij, P. Y. (2003). Fundamentals of Powder Diffraction and Structural Characterization of Materials (Springer, New York).

Polyanskaya, T. M., Borisov, S. V., and Belov, N. V. (1969). "Crystal structure of $\mathrm{Pr}_{3} \mathrm{WO}_{6} \mathrm{Cl}_{3}$," Dokl. Akad. Nauk SSSR 187, 1043-1046.

Putz, H., Schon, J. C., and Jansen, M. (1999). "Combined method for $a b$ initio structure solution from powder diffraction data," J. Appl. Crystallogr. 32, 864-870.

Rietveld, H. M. (1969). "A profile refinement method for nuclear and magnetic structures," J. Appl. Crystallogr. 2, 65-71.

Rius, J. (2004). "Advances and some recent applications of the origin-free modulus sum function," Z. Kristallogr. 219, 826-832.

Rodriguez-Carvajal, J. (1993). "Recent advances in magnetic-structure determination by neutron powder diffraction," Physica B 192, 55-69.

Spek, A. L. (2003). "Single-crystal structure validation with the program PLATON," J. Appl. Crystallogr. 36, 7-13.

Stephens, P. W. and Huq, A. (2002). "PSSP: An open source powder structure solution program for direct space simulated annealing," Trans. Am. Crystallogr. Assoc. 37, 127-144.

Yanovskii, V. K. and Voronkova, V. I. (1975). "Crystallography and properties of lanthanum oxytungstate, $\mathrm{La}_{2} \mathrm{WO}_{6}$," Sov. Phys. Crystallogr. 20, 354-355.

Zhu, J. H., Wu, H. X., and Le Bail, A. (1999). "Structure of $\left[\mathrm{Co}\left(\mathrm{NH}_{3}\right)_{5} \mathrm{CO}_{3}\right] \mathrm{NO}_{3} \cdot \mathrm{H}_{2} \mathrm{O}$, , Solid State Sci. 1, 55-62. 